\title{
Avaliação fisico-química e quantificação de micotoxinas em silagens de resíduo de cervejaria do estado do Rio de Janeiro
}

\author{
Leonardo de Assunção Pinto ${ }^{1}$, Wagner Ladeira², Marcos Aronovich ${ }^{3}$, Victor Moebus Farias ${ }^{4}$, \\ Felipe Braz Nielsen Köptcke ${ }^{5}$, Luiz Antonio Moura Keller ${ }^{6}$
}

\section{Resumo}

A ensilagem é uma prática comum para preservar forragens no Brasil, porém, condições inadequadas de armazenamento podem levar a contaminação por fungos com produção de micotoxinas. As análises deste trabalho foram realizadas nos laboratórios do Centro Estadual de Pesquisa de Alimentos (CEPQA) na PESAGRO-RJ com objetivo de avaliar os parâmetros fisico- químicos das silagens, identificar sua micobiota e quantificar Aflatoxinas Totais (AFs), Ocratoxina A(OTA), Fumonisina B1 (FB1) e Zearalenona (ZEA) possivelmente presentes nas amostras, utilizando fluorímetro de imunoafinidade e cromatografia (IAC). Foram aplicados três tratamentos (1 - Residuo in natural; 2 - Inoculante comercial; 3 - Inoculante produzido no CEPQA), não sendo observadas diferenças significativas nos padrões físico-químicos entre a fermentação natural e utilizando inoculantes microbiológicos. Quanto a carga microbiana, todas as amostras se encontram acima das regulamentações nacionais e internacionais $\left(\geq 10^{4} \mathrm{UFC} / \mathrm{g}^{-1}\right)$. Os níveis de AFs não diferiram, com intervalo de $4,5 \mu \mathrm{g} \mathrm{kg}^{-1}$ a $100 \mu \mathrm{g} \mathrm{kg}^{-1}$ em amostras pré e pós-fermentação, respectivamente, enquanto os níveis de FB1 e ZEA encontrados em amostras de pré-fermentação foram maiores do que na pós- fermentação com intervalo de 0,3 ng kg-1 a 2,0 ng $\mathrm{kg}^{-1}$, mas sem diferir estaticamente. Há também níveis de toxinas e índices de contaminação fúngica não preconizados pela legislação vigente. A aplicação de produtos microbiológicos oferece uma boa opção para ensilamento desde que seja realizado monitoramento contínuo para garantir inocuidade, sendo ainda necessária uma legislação atualizada e ações de treinamento dos técnicos de campo.

Palavras-chave: Aflatoxina; fumonisina; zearalenona; silagem de resíduo de cervejaria.

\section{Introdução}

Um dos principais problemas encontrados na criação de bovinos é o alto valor das rações e insumos, bem como os longos períodos de seca, quando a quantidade e qualidade das pastagens diminuem acentuadamente, reduzindo ou inviabilizando a produção de leite em escala comercial.

A produção de silagem é uma das técnicas mais viáveis e utilizadas pelos produtores na tentativa de fornecer alimento durante os períodos críticos do ano (CARDOSO, 1995). A ensilagem é um método de conservação de forragens de forma a preservar o conteúdo de matéria seca (MS) e o seu valor nutricional. Esta pode favorecer o crescimento de vários tipos de micro-organismos, sendo que a maioria pode reduzir o valor nutricional do alimento, quando produzida de maneira inadequada (DOS SANTOS et al., 2013). Apesar dos ganhos nutricionais para o rebanho, problemas relacionados no processamento, armazenamento e fornecimento aos animais, podem vir a prejudicar o desempenho dos animais.

Manter o ambiente em anaerobiose durante a fase de fermentação e armazenamento, bem como a estabilidade aeróbia durante a fase de fornecimento no cocho, se torna imprescindível para a preservação da qualidade microbiológica e do valor nutricional do material ensilado. Os efeitos do uso de inoculantes bacterianos sobre a estabilidade aeróbia de silagens podem vir a solucionar parte destes problemas.

Inoculantes à base de bactérias produtoras de ácido láctico tem sido empregados com resultados satisfatórios, dando retorno econômico aos produtores através de uma melhor produtividade e qualidade no material ensilado. Dessa forma, entende-se que, para manter a boa qualidade de alimentos ensilados, são necessárias medidas adequadas, a fim de se evitar problemas à saúde animal, assim como perdas econômicas.

A fim de minimizar os custos, sem comprometer a produtividade do rebanho, a utilização de subprodutos agroindustriais vem se tornando uma prática constante nas ensilagens em muitas propriedades. A cevada é usada em bebidas fermentadas e, embora seus maiores atrativos sejam seus valores de proteína e amido, capazes de gerar alta energia metabólica, seu bagaço tem proporcionado aumento de $30 \%$ na produção ao ser incluído na alimentação de vacas leiteiras (Abreu et al., 2004).

\footnotetext{
*Graduando em Farmácia - Faculdade de Farmácia - Universidade Federal Fluminense - Niterói, RJ. Bolsista de Iniciação Científica pela Fundação de Amparo à Pesquisa do Estado do Rio de Janeiro (FAPERJ) - E-mail: leonardoap@id.uff.br

**Pós-graduação em Zootecnia - Instituto de Zootecnia - Universidade Federal Rural do Rio de Janeiro - Seropédica, RJ.

***Pesquisador da Empresa de Pesquisa Agropecuária do Estado do Rio de Janeiro (PESAGRO-RJ) - Niterói, RJ.

${ }^{* * * *}$ Doutorando do curso de Higiene Veterinária e Tecnologia de Produtos de Origem Animal - Faculdade de Veterinária - Universidade Federal Fluminense Niterói, RJ. Bolsista da Coordenação de Aperfeiçoamento de Pessoal de Nível Superior (CAPES).

*****Graduando em Farmácia - Faculdade de Farmácia - Universidade Federal Fluminense - Niterói, RJ. Bolsista de Iniciação Científica pelo Programa Institucional de Bolsas de Iniciação Cientifica da UFF (PIBIC-UFF).

****** Departamento de Zootecnia e Desenvolvimento Agrossocioambinetal Sustentável - Faculdade de veterinária - Universidade Federal Fluminense - Niterói, RJ.
} 
Tendo em vista esses fatores, objetiva-se avaliar os padrões e parâmetros fisco químicos das silagens de cevada preparadas, bem como analisar a micobiota, isolando e identificando espécies dos gêneros Aspergillus, Penicillium e Fusarium, potencialmente produtoras de micotoxinas, e quantificar Aflatoxinas Totais (AFs), Ocratoxina A (OTA), Fumonisina B1 (FB1) e Zearalenona (ZEA) que possam estar presentes nas amostras, através de técnicas cromatográficas.

\section{Material e Métodos}

A confecção dos silos ocorreu nos laboratórios da Empresa de Pesquisa Agropecuária do Estado do Rio de Janeiro (PESAGRO-RIO) e Universidade Federal Fluminense. Como micro- organismos inoculantes foram utilizadas duas cepas isoladas de silagens de milho. Estas cepas foram trabalhadas para desenvolvimento de potencial de biofermentação e probiótico (L. rhamnosus - RC007 e L. plantarum - RC009). As cepas referência encontram-se depositadas na coleção National University of Rio Cuarto, Cordoba, Argentina. Além disso, foram utilizados três inoculantes utilizados pelo mercado, testando sua viabilidade em comparação a micro-organismos selecionados a campo.

O material para confecção da silagem foi coletado pósprocessamento em cervejarias parceiras. O material foi espalhado sobre uma lona plástica e o inoculante aplicado conforme indicações do produto comercial, por meio de borrifador manual, utilizando água não clorada e retirando amostras para análise da concentração inicial do inoculante. Após a aplicação do inoculante e sua homogeneização, o material foi ensilado em silos confeccionados com tubos de PVC de 0,5 metros de comprimento e $100 \mathrm{~mm}$ de diâmetro sendo fechados com tampas providas de válvula para eliminação dos gases. Os silos experimentais foram armazenados em temperatura ambiente e abertos com 2, 7, 30, 60 e 90 dias para as análises de cor e retirada de material danificado por presença de fungos. $O$ restante do material foi quantificado e homogeneizado para retirada de amostras para as análises pertinentes.

O experimento foi elaborado com cinco produtos usando dosagens comerciais recomendadas para atingir a concentração de $1 \times 10^{8} \mathrm{UFC} / \mathrm{g}$ de produto e avaliadas em todo o processo com relação a UFC/g e células viáveis. Os produtos foram codificados e identificados como Produto A: RC 007; Produto B: RC 009; Produto C: Inoculante comercial A; Produto D: Inoculante comercial B; Produto E: Inoculante comercial C. Usando esses produtos foram feitos 6 tratamentos incluindo o grupo controle, assim, Tratamento 1: controle (sem uso de inoculante); Tratamento 2: Produto A; Tratamento 3: Produto B; Tratamento 4: Produto C; Tratamento 5: Produto D; Tratamento 6: Produto E.

O estudo foi feito com cinco tempos de fermentação e quatro repetições para cada um dos produtos, totalizando 100 silos.

Após homogeneização e descarte do material das extremidades dos silos, foram retiradas amostras de 500 gramas. Parte destas amostras foi processada para as análises físicas e de micobiota enquanto outra parte foi mantida a $-5^{\circ} \mathrm{C}$ até o momento das análises micotoxicológicas.
As análises de controle de qualidade físico-químico incluíam: Matéria seca em estufa de circulação forçada de ar à $105^{\circ} \mathrm{C} / 24 \mathrm{~h}$; proteína Bruta por método de Micro Kjedahl; pH em potenciômetro; temperatura utilizando termômetro de penetração; atividade Aquosa (Aw); fibra em detergente neutro e em detergente ácido, ambos em determinador (Velp); lignina pelo método de permanganato; nitrogênio amoniacal como percentual do nitrogênio total; Digestibilidade "in vitro" pelo método de Tille Terry (AOAC, 1990).

Em sequência, eram quantificados os fungos em unidades formadoras de colônias por grama (ufc g-1) segundo a metodologia de diluição decimal seriada em placas (PITT; HOCKING, 1997) usando como meios de cultivo: Ágar Dicloran Glicerol (DG18) para fungos xerófilos (PITT; HOCKING 1997); meio Dicloran Rosa de Bengala Cloranfenicol Ágar (DRBC) para número total de fungos e Nash-Snyder Ágar (NSA) para fungos do gênero Fusarium (NELSON et al., 1983).

A identificação de gênero de todas as colônias fúngicas foi realizada seguindo características macro e microscópicas (Samson et al., 2000). As colônias de Aspergillus e Penicillium sofreram subcultivo em meio CYA e em tubos inclinados MEA, além de CY20S para Aspergillus spp. e G25N para Penicillium spp. As colônias de Fusarium utilizaram Ágar Folha de Bananeira (BLA) e, em tubo inclinado, Ágar Batata Dextrose (BDA), para uma posterior diferenciação de espécies.

A identificação de espécies foi segundo as chaves taxonômicas de cada grupo: Klich (2002) para o gênero Aspergillus, Pitt; Hocking (1997) para o gênero Penicillium e Nelson; Toussoun; Marasas (1983) para espécies pertencentes ao gênero Fusarium.

A descoberta e quantificação de Aflatoxinas Totais (AFs), Ocratoxina A (OTA), Fumonisina B1 (FB1) e Zearalenona (ZEA) foi usando purificação em colunas de imunoafinidade específicas, com triagem em fluorímetro modelo $\mathrm{VICAM}^{\circledR}$ série 4 ex segundo metodologia do manual de métodos oficiais de análises da AOAC (1990). O extrato obtido foi evaporado até secura e, para purificação, se utilizou colunas de imunoafinidade para purificação e posterior detecção em HPLC, sistema JASCO ${ }^{\circledR}$ modelo LC 2000, munido com detector de fluorescência e coluna de sílica C18, modelo SUPELCO ${ }^{\circledR}$.

A análise estatística dos dados foi feita por análise de variância (ANOVA) na transformação dos dados em escala logarítmicos e foi aplicado o teste de Tukey para comparar as médias de cada tratamento avaliado, além de comparar os níveis microbiológicos e de micotoxinas nos diferentes tratamentos ensilados (Statistica for Windows 5.0 SAS System for Windows $\left.{ }^{\circledR}\right)$.

\section{Resultados e Discussão}

Os valores observados na tabela 1 indicam heterogenicidade do material ressaltando a necessidade de avaliação continua para atender os padrões. Em análise preliminar podemos estimar a possível ocorrência de contaminação fúngica prejudicial ao uso e processamento de grãos e ao uso da ração (KELLER et al., 2012), mesmo que a média indique uma qualidade nutritiva satisfatória para os produtos analisados. 
Tabela 1: Parâmetros das análises físico-químicas das amostras de silagem

\begin{tabular}{cccccc}
\hline $\begin{array}{c}\text { Amostras } \\
\text { Silagem }\end{array}$ & Matéria seca & Proteína & Cinzas $^{3}$ & Lipídeos $^{4}$ & Fibras $^{5}$ \\
\hline $\begin{array}{c}\text { Valores de } \\
\text { Média Mínimos }\end{array}$ & $39,44 \% \pm 0,73 \%$ & $13,48 \% \pm 0,26 \%$ & $0,78 \% \pm 0,09 \%$ & $8,1 \% \pm 0,6 \%$ & $18,48 \% \pm 0,26 \%$ \\
$\quad \begin{array}{l}\text { Valores } \\
\text { Máximos } \\
\text { Valores }\end{array}$ & $27,60 \% \pm 0,53 \%$ & $2,81 \% \pm 0,26 \%$ & $0,58 \% \pm 0,09 \%$ & $2,2 \% \pm 0,6 \%$ & $8,81 \% \pm 0,26 \%$ \\
& $50,45 \% \pm 0,72 \%$ & $17,85 \% \pm 0,26 \%$ & $0,9 \% \pm 0,09 \%$ & $11,0 \% \pm 0,6 \%$ & $27,85 \% \pm 0,26 \%$
\end{tabular}

1. Matéria Seca; 2. Protéina Bruta Total; 3. Sais minerais residuais; 4. Teor de Lipídeos Totais; 5. Teor de Fibras Digeríveis em Detergente Neutro

Considerando todas as amostras analisadas, foram isoladas e identificadas 35 cepas na micobiota (tabela 2) com predominância de fungos filamentosos. Foram identificados Aspergillus, Fusarium, Penicillium, Cladosporium, Alternaria, e Curvularia, sendo espécies potecialmente produtoras de micotoxinas, as do gênero Aspergillus, Penicillium e Fusarium.

Tabela 2: Frequência (\%) de gêneros de fungos nas amostras de silagem analisadas

\begin{tabular}{ccc}
\hline Gênero fúngico & $\begin{array}{c}\text { Quantidade em } \\
\text { UFC. } g^{-1}\end{array}$ & Frequência (\%) \\
\hline Aspergillus $s p$. & 16 & 45,7 \\
Penicillium $s p$. & 3 & 8,6 \\
Cladosporium $s p$. & 3 & 8,6 \\
Mucor $s p$. & 2 & 5,7 \\
Fusarium $s p$. & 6 & 17,1 \\
Curvularia $s p$. & 2 & 5,7 \\
Alternaria $s p$. & 3 & 8,6 \\
Total & 35 & 100,0 \\
\hline
\end{tabular}

É extremamente importante ressaltar que a carga fúngica de todas as amostras estava acima de recomendações e regulamentações nacionais e internacionais $\left(\geq 10^{4} \mathrm{UFC} / \mathrm{g}^{-1}\right)$ (BRASIL, 1988; GMP, 2008), podendo causar danos aos animais. Os efeitos geralmente se apresentam como infecções crônicas e não tem sintomas clínicos específicos.
O meio DG18 é um meio de cultura recomendado para amostras com baixa aw permitindo o crescimento de fungos xerofílicos, aqueles que suportam baixa aw, sem reduzir ou limitar seu crescimento. Todas as amostras analisadas apresentaram contagens média a altas neste meio, demostrando a possibilidade de risco a saúde, já que entre os xerofílicos estão incluídos dois dos principais gêneros toxígenos, Aspergillus e Penicillium.

Do gênero Aspergillus foram identificadas as respectivas espécies: A. flavus, A. parasiticus, A.oryzae, A. fumigatus, $A$. niger agregado. Do gênero Penicillium, P. citrinum. Do gênero Fusarium, $F$. verticillioides e F. chlamydosporum. Não foi constatada diferença estatística significativa $(P \geq 0,005)$ entre as amostras em relação os produtos testados.

As micotoxinas foram extraídas das amostras e a triagem das micotoxinas com o uso do fluorímetro revelou uma boa relação na avaliação dos dados com os níveis quantificados por HPLC. Os dados obtidos em HPLC considerando apenas a quantificação média entre todas as amostras antes e depois da fermentação estão dispostos na tabela 3 considerando as legislações internacionais, já que, para silagem utilizada na alimentação de bovinos, não existe legislação brasileira específica.

Após a fermentação ocorre um aumento perceptível das AFB1 enquanto as concentrações de ZEA e FB1 sofrem redução. O aumento de aflatoxinas está em acordo com o esperado, vide que, quase metade das colônias encontradas pós-fermentação pertencem a esse gênero. Já a redução das demais micotoxinas pode estar ligado a uma competição entre as diferentes espécies de fungo ou simplesmente a ensilagem feita de forma eficiente reduzindo o crescimento desse gênero e, consequentemente a produção destas micotoxinas.

Tabela 3: Níveis de micotoxinas encontrados nas amostras de silagens pré e pós-fermentação

\begin{tabular}{ccccc}
\hline Amostra & Micotoxina & $\begin{array}{c}\text { Frequência de } \\
\text { Contaminação (\%) }\end{array}$ & $\left.\mathbf{( \mu g ~ g ~}^{-\mathbf{1}}\right)$ & $\begin{array}{c}\text { Amostras acima do limite } \\
\text { internacional }(\%)^{*}\end{array}$ \\
\hline Pré-fermentação & AFB1 & 31 & $0.2-4.5$ & 0 \\
& FB1 & 20 & $30.0-200.00$ & 23 \\
& ZEA & 26 & $25.0-185.00$ & 12 \\
Pós-fermentação & AFB1 & 40 & $2.00-100.00$ & 84 \\
& FB1 & 30 & $15.0-132.00$ & 13 \\
& ZEA & 20 & $30.0-151.00$ & 8 \\
\hline "Limite: $0.02 \mathrm{\mu g} \mathrm{g}^{-1} \mathrm{AFB}_{1}(\mathrm{GMP}, 2008), 50 \mathrm{ng} \mathrm{g}^{-1} \mathrm{FB}_{1}, 12$ ng g $^{-1}$ ZEA (CE, 2006).
\end{tabular}




\section{Conclusões}

Dos padrões e parâmetros físico-químicos avaliados nas preparações de silagem, não se observa diferenças enquanto todas as amostras se encontram acima das regulamentações nacionais e internacionais de carga microbiana $\left(\geq 10^{4} \mathrm{UFC} / \mathrm{g}^{-1}\right)$ (BRASIL, 1988; GMP, 2008).

Os níveis de aflatoxinas totais se encontram dentro dos limites da legislação brasileira, porém algumas amostras estão em desacordo com legislações internacionais (BRASIL, 1988; GMP, 2008). Além

\section{Referências}

ABREU, M.B.; VIEIRA, A.A.; GOMES, M.P.; LIMA, T.S.; MATOS, E.S.; BEZERRA, E.S. Alimentação de suínos nas fases de crescimento e terminação com dietas contendo niveis crescentes de bagaço de cevada. Anais de Zootec, Brasília, DF, 2004.

OFFICIAL METHODS OF ANALYSIS, AOAC - ASSOCIATION OF OFFICIAL ANALYTICAL CHEMISTS. Gaithersburg, Agresti, 1990.

BRASIL. Portaria n. 7 de 09 de novembro de 1988. Padrões mínimos de matéria prima empregada na alimentação animal. Diário Oficial da União, Brasília, DF, 14 de novembro de 1988.

CARDOSO, E. G.; SILVA, J. M. Silos, silagem e ensilagem. Embrapa Gado de Corte, Campo Grande, MS, 1995.

CE. COMUNIDADE EUROPÉIA. Regulamento № 401/2006 de 23 de Fevereiro de 2006, relativo aos métodos de amostragem e de análise para o controlo oficial dos teores de micotoxinas nos géneros alimentícios. Journal Oficial da União Européia, 2006.

DOS SANTOS, S. F. et al. Principais tipos de silos e microrganismos envolvidos no processo de ensilagem. Veterinária Notícias, v. 19, n. 2, 2013. disso, há níveis de toxinas quantificados e índices de contaminação fúngica que não são preconizados pela legislação brasileira vigente (BRASIL, 1988), reforçando a necessidade de uma legislação atualizada e ações de para treinamento dos técnicos de campo.

A aplicação de produtos microbiológicos oferece uma boa opção para o processo de ensilamento, auxiliando na manutenção dos valores fisico-quimicos e sem alterar significativamente a microbiota, porém, é imprescindível que seja realizado monitoramento contínuo para garantir inocuidade e aprimorar esta importante atividade da pecuária brasileira.

GMP + Certification Scheme Animal Feed Sector. 2006. Appendix 1: Product standards (including residue standards). The Hague, the Netherlands: Products chap Diervoeder. p. 1 -39. 2008.

KELLER L.A.M., KELLER, K.M.; MONGE, M.P.; PEREYRA, C.M.; ALONSO, V.A.; CAVAGLIERI, L.R. ; CHIACCHIERA, S.M.; Rosa, C.A.R. . Gliotoxin contamination in and pre- and post-fermented corn, sorghum and wet brewer's grains silage in São Paulo and Rio de Janeiro State, Brazil. Journal of Applied Microbiology, v. 112, p. 865-873, 2012.

$\mathrm{KLICH}, \mathrm{M} . \mathrm{A}$. Identification of common Aspergillus species. Netherlands: Central bureau voor Schinmelcultures, 2002. 116p.

NELSON, P.T.; TOUSSOIN, T.A.A.; MARASAS, W.E.O. Fusarium species: An illustrated manual for identification. London: The Pennsylvania State University Press, 1983.

PITT, J.L.; HOCKING, A.D. Fungi and food. London: Black Academia \& Professional Chapmam \& Hall, 1997. 593p.

SAMSON, R. A.; VAN REENEN-HOEKSTRA, E. S.; FRISVAD, J. C.; FILTENBORG, O. Introduction to Food and Airborne Fungi. 6 ed. Netherlands: Centraal bureau Voor Schimmelcultures, 2000. $388 \mathrm{p}$. 